\title{
Fabrication of Diamond Membranes by Femtosecond Laser Ablation for MEMS Sensor Applications ${ }^{\dagger}$
}

\author{
Johann Zehetner 1,*, Alexander Kromka ${ }^{2}$, Tibor Izsák ${ }^{2,3}$, Gabriel Vanko ${ }^{3}$, Lenka Gajdošová ${ }^{1}$ \\ and Stephan Kasemann ${ }^{1}$ \\ 1 Research Center for Microtechnology, Vorarlberg University of Applied Sciences, 6850 Dornbirn, Austria; \\ lenka.gajdosova@fhv.at (L.G.); stephan.kasemann@fhv.at (S.K.) \\ 2 Institute of Physics, Czech Academy of Sciences, 16200 Prague 6, Czech Republic; kromka@fzu.cz (A.K.); \\ tibor.izsak@savba.sk (T.I.) \\ 3 Institute of Electrical Engineering, Slovak Academy of Sciences, 84104 Bratislava, Slovakia; \\ gabriel.vanko@savba.sk \\ * Correspondence: johann.zehetner@fhv.at \\ † Presented at the 4th International Conference nanoFIS 2020-Functional Integrated nano Systems, \\ Graz, Austria, 2-4 November 2020.
}

Published: 10 December 2020

\begin{abstract}
We present the feasibility in fabricating membranes and cantilevers made of diamond grown on $\mathrm{Si} / \mathrm{SiO}_{2}$ substrates by femtosecond laser ablation. In the ablation process, we generated nano- and microstructures on the membrane surface. Such laser-induced periodic surface structures (LIPSS) are useful in tailoring the surface chemistry. In combination with wet or reactive ion etching, smooth membranes were generated.
\end{abstract}

Keywords: MEMS; diamond; laser ablation; laser-induced periodic surface structures

\section{Introduction}

Diamond and other wide-bandgap materials can be effectively used in specialized sensor applications. However, their micromachining is somewhat challenging due to their chemical resistivity and mechanical hardness. Femtosecond laser ablation provides a precise fabrication of diamond without overheating of the ablated material as visible and near-infrared light is generally not absorbed. Recently, we demonstrated a laser ablation method providing $\mathrm{SiC}$ membranes and laser-induced periodic surface structures (LIPSS) in the micro- and nanometer range for MEMS and sensor applications [1-3]. We observed the formation of high-spatial frequency LIPSS (HSFL) on the backside of metal-coated $\mathrm{SiC}$ membranes [2,3]. This enhances the functionalization of diamond membranes or cantilevers for specific chemical sensor applications, e.g., gas sensors, solar cells photocatalysis, electronic devices and batteries. In this work, fabrication of diamond membranes by the laser ablation technique with regard to the issues and solutions is presented.

\section{Materials and Methods}

The diamond films were deposited on $525 \mu \mathrm{m}$ thick (100) Si substrates (covered by $1.3 \mu \mathrm{m}$ thick $\mathrm{SiO}_{2}$ layer) with an ellipsoidal cavity microwave plasma reactor. Before diamond chemical vapor deposition (CVD), the substrates were ultrasonically seeded by nanodiamond powder in DI water. The deposition conditions were as follows: MW power $4.2 \mathrm{~kW}$, pressure $90 \mathrm{mbar}$, gas mixture $5 \%$ $\mathrm{CH}_{4}$ and $1.5 \% \mathrm{CO}_{2}$ to $\mathrm{H}_{2}$, deposition temperature $960{ }^{\circ} \mathrm{C}$, deposition time 16 and 32 hours, respectively, corresponding to diamond film thicknesses of approximately 7.2 and $21.7 \mu \mathrm{m}$. For laser ablation, a femtosecond (fs) laser (SPIRIT from Spectra Physics) was applied. For the experiments, 
we used the $1 \mathrm{MHz}$ and $520 \mathrm{~nm}$ setting but picked only every tenth pulse to obtain an ablation pulse frequency of $100 \mathrm{kHz}$. The line distance between consecutive scans was $5 \mu \mathrm{m}$ and the respective focus diameter of the $170 \mathrm{~mm}$ scanner lens was approximately $18 \mu \mathrm{m}$. The scan speed was set to $500 \mathrm{~mm} / \mathrm{s}$.

\section{Results}

The formation of pinholes on the membrane and elongated cavities at the corners of the bore in Si can be significantly reduced by rotating the direction of the laser polarization during the ablation procedure [3]. Due to the sufficient higher ablation threshold of diamond with respect to $\mathrm{Si}$, we reduced the bore diameter in three steps from 2 to 1.5 to $1 \mathrm{~mm}$ (to attenuate the effect of the cavity formation at the corner, see Figure 1). An entire production of a membrane by selective laser ablation was possible after the removal of about $525 \mu \mathrm{m} \mathrm{Si}$ which required at least 700 consecutive ablation scans. This gave time to generate laser-induced surface structures and pinholes. Si masking effects had only a minor impact on the surface quality of the predominately selectively ablated diamond (Figure 1b). In the lower diagonal section of Figure 1b, the $\mathrm{SiO}_{2} / \mathrm{Si}$ layers on top of the diamond membrane were removed. The pinholes in the Si structure caused no excessive ablation at the diamond surface, and only shallow notches about $1 \mu \mathrm{m}$ in diameter were generated. It is feasible to selectively remove the remaining $\mathrm{SiO}_{2}$ layer in the ablation process without destroying the $22 \mu \mathrm{m}$ thick diamond membrane. In an earlier work, we produced $14 \mu \mathrm{m}$ thick glass membranes [4], but the material properties of the deposited diamond layer on $\mathrm{Si} / \mathrm{SiO}_{2}$ are promising to generate even thinner membranes in future attempts by laser ablation only.

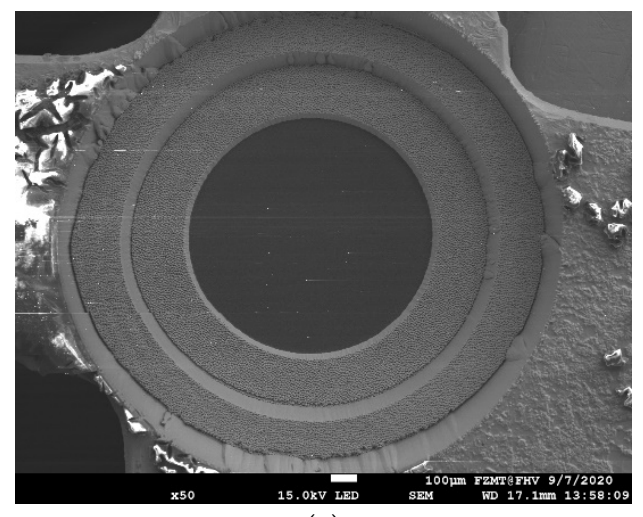

(a)

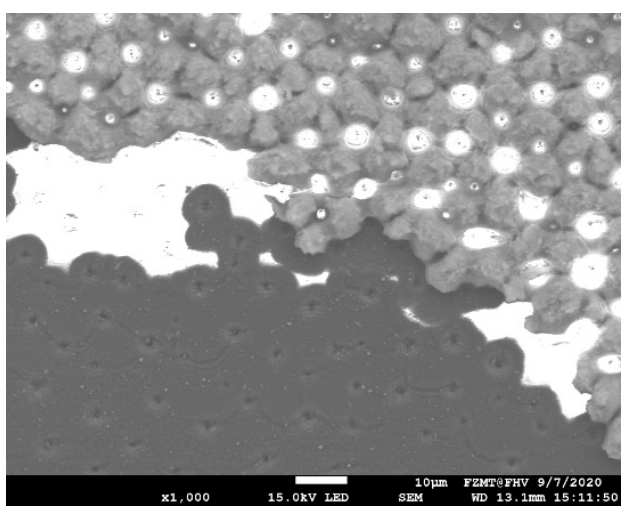

(b)

Figure 1. SEM micrograph of (a) $22 \mu \mathrm{m}$ thick, laser-generated diamond membrane and (b) $1 \mu \mathrm{m}$ notches in the diamond layer due to pinholes in Si.

Author Contributions: Conceptualization, A.K. and G.V.; methodology, J.Z., S.K. and T.I.; formal analysis, J.Z. L.G.; investigation, T.I., J.Z., G.V.; writing - original draft preparation, J.Z.; writing - review and editing, G.V., T.I.; visualization, L.G.; supervision, A.K. All authors have read and agreed to the published version of the manuscript.

Funding: This research was funded by the Programme for Funding Multilateral Scientific and Technological Cooperation Projects in the Danube Region, grant No. DS-FR-19-0051 (grant No. 8X20035).

Conflicts of Interest: The authors declare no conflict of interest.

\section{References}

1. Vanko, G.; Hudek, P.; Zehetner, J.; Dzuba, J.; Choleva, P.; Kutiš, V.; Vallo, M.; Rýger, I.; Lalinský, T. Bulk micromachining of SiC substrate for MEMS sensor applications. Microelectron. Eng. 2013, 110, 260-264.

2. Zehetner, J.; Kraus, S.; Lucki, M.; Vanko, G.; Dzuba, J.; Lalinsky, T. Manufacturing of membranes by laser ablation in $\mathrm{SiC}$, sapphire, glass and ceramic for $\mathrm{GaN} /$ ferroelectric thin film MEMS \& pressure sensors. Microsyst. Technol. 2016, 22, 1883-1892. 
3. Zehetner, J.; Vanko, G.; Choleva, P.; Dzuba, J.; Ryger, I.; Lalinsky, T. Using of laser ablation technique in the processing technology of GaN/SiC based MEMS for extreme conditions. In Proceedings of the Tenth International Conference on Advanced Semiconductor Devices and Microsystems, Smolenice, Slovakia, 20-22 October 2014; pp. 1-4, doi:10.1109/ASDAM.2014.6998693.

4. Zehetner, J.; Vanko, G.; Dzuba, J.; Lalinsky, T. Femtosecond Laser Processing of Membranes for Sensor Devices on different Bulk Materials. Adv. Electr. Electron. Eng. 2017, 15, 561.

Publisher's Note: MDPI stays neutral with regard to jurisdictional claims in published maps and institutional affiliations.

(C) 2020 by the authors. Licensee MDPI, Basel, Switzerland. This article is an open access article distributed under the terms and conditions of the Creative Commons Attribution (CC BY) license (http://creativecommons.org/licenses/by/4.0/). 